\title{
Luzes e Sombras: um olhar de Keynes sobre a esquerda
}

\author{
Lights and Shadows: a Keynes's view on the left
}

JOÃO SICSÚ *;**

\begin{abstract}
RESUMO: A posição política e ideológica de J. M. Keynes é de difícil classificação. O objetivo do artigo é identificar sua posição. Nos dias de hoje, há uma forte identificação das ideias de Keynes com parte da esquerda. Por outro lado, há na literatura econômica especializada posições que o colocam de forma bastante nítida bem afastado da esquerda marxista/comunista. Parece, entretanto, que a relação de Keynes e suas ideias com a cultura da esquerda comunista estaria marcada por profundas aderências e rejeições. Keynes adotou posições que eram aparentemente dúbias e pendulares. Em verdade, Keynes era um iluminista, um intelectual elitista, que tinha uma utopia de justiça social, bem-estar material e liberalismo político. Esse é o motivo por que hoje ele é admirado pela esquerda reformista e radical.
\end{abstract}

PALAVRAS-CHAVE: Ideologia de Keynes; Keynes e a esquerda; Utopia de Keynes.

ABSTRACT: It is not easy to classify J. M. Keynes's ideological and political position. The purpose of this article is to identify his position. Nowadays, part of the left-wing identifies itself with his positions. On the other hand, there are some specialised economic literature positions that clearly show Keynes's ideas are far from those of the Marxist/Communist left. However, it seems that Keynes's relationship and his ideas with the culture of the communist left would be marked by deep adherences and rejections. Keynes apparently adopted dubious and pendular positions, but in fact, Keynes was an illuminist, an elitist intellectual, who had a utopia of social justice, material welfare and political liberalism. This is why, he is nowadays admired by the radical and reformist left.

KEYWORDS: Keynes's ideology; Keynes and the left-wing; Keynes's Utopia.

JEL Classification: B31; A31; A13.

\footnotetext{
* Professor do Instituto de Economia da Universidade Federal do Rio de Janeiro - IE-UFRJ, Rio de Janeiro/RJ, Brasil. E-mail: joaosicsu@gmail.com. ORCID: 0000-0003-3997-7129.

* O autor gostaria de agradecer as contribuições valiosas de Eduardo da Motta e Albuquerque e, também, de dois pareceristas anônimos. Valem as observações de praxe. Submetido 5/Fevereiro/2019; Aprovado: 4/Setembro/2019.
} 


\section{INTRODUÇÃO}

J. M. Keynes elaborou diagnósticos e instrumentos visando aumentar a eficiência de uma economia que deveria oferecer bem-estar a todos. Dos anos 1940 aos anos 1970, muitas das ideias e políticas de Keynes foram aplicadas mundo afora. Contudo, desde os anos 1980, o debate econômico sobre eficiência tem sido substituído pelo debate político/ideológico de rotulação (esquerda ou direita) de economistas e políticas econômicas.

Nos dias de hoje, há uma identificação das ideias de Keynes com a esquerda. Por exemplo, os programas de Jeremy Corbyn, para Grã-Bretanha, e de Jean-Luc Mélenchon, para a França, são considerados keynesianos.

Por outro lado, há na literatura especializada em Keynes (por exemplo, Harrod, 1958 e Skidelsky, 1994), posições que o colocam de forma bastante clara afastado da esquerda - aqui entendida como uma cultura que envolve a adoção das ideias de Karl Marx, a defesa da revolução bolchevique de 1917, seus métodos de governo e seus desdobramentos estalinistas. A esquerda aqui referida é a esquerda comunista.

Serão utilizados os termos esquerda comunista (tal como já definido) e esquerda radical e reformista. Essa última será usada para designar posições tais como as de Corbyn e Mélenchon. São políticos libertários, que lutam por reduções das desigualdades de renda e riqueza, não pregam a violência como método e priorizam a luta de ideias. Contudo, o artigo trata principalmente das relações de Keynes com a esquerda comunista. ${ }^{1}$

Parece que a relação de Keynes e suas ideias com a cultura da esquerda comunista estaria marcada por luzes e sombras. Em relação aos bolcheviques, Keynes admirou Vladimir Lênin e antipatizou com Josef Stálin. Keynes valorizou os Planos Quinquenais de Stálin e repudiou seus métodos de governança. Keynes considerou valorosa as contribuições de Marx para o entendimento do funcionamento do capitalismo. No entanto, não aceitou as consequências apontadas por Marx que daí poderiam resultar. Keynes rejeitou a luta de classes e defendeu a luta de ideias. Keynes adotou como método o gradualismo e não a ruptura revolucionária. Keynes defendeu como ponto de chegada o liberalismo político (democracia e plena liber-

\footnotetext{
${ }^{1}$ Tais definições são as mesmas utilizadas por Bresser-Pereira (2006) que apresentou uma taxonomia das esquerdas, entre elas, destacou: (a) "A extrema esquerda é revolucionária, não vê na democracia existente senão uma forma de dominação: pretende assumir o poder revolucionariamente para, em seguida, implementar o que denomina socialismo - o que seria mais correto chamar de estatismo" (Bresser-Pereira, 2006, s/ numeração de página) - essa esquerda equivale ao que denominamos esquerda comunista - e (b) “[...] uma esquerda reformista, que durante o século XX foi social-democrata, mas está se transformando em centro-esquerda social-liberal, na medida em que [alguns] partidos de esquerda na Europa [...] [pretendem reformar] suas economias e seu Estado no sentido de manter a garantia aos direitos sociais e aprofundar a igualdade, ao mesmo tempo que aceitam um papel mais ativo de mercados regulados na coordenação do sistema" (Bresser-Pereira, 2006, sem numeração de página) - essa esquerda equivale ao que rotulamos de esquerda reformista e radical.
} 
dade) associado ao bem-estar material para todos. Essas são algumas das principais conclusões do artigo.

Apesar dos aparentes movimentos pendulares e dubiedade, Keynes hoje é admirado por grande parte da esquerda radical e reformista. O debate dos nossos tempos ideologizou a discussão sobre a economia e, então, Keynes foi colocado à esquerda. O debate sobre a eficiência de suas políticas perdeu importância. É preciso, então, destrinchar o emaranhado de avaliações, elogios, posicionamentos e críticas feitas por Keynes à esquerda comunista para que possamos identificar a sua posição. Esse é o objetivo do artigo. Mais: ainda que as ideias de Keynes tenham sido apropriadas por parte da esquerda, é necessário revelar que progressismo existiu em suas ideias para que possamos identificar a qual esquerda ele pode estar adaptado. A conclusão é que as ideias de Keynes não têm sido úteis à esquerda comunista, mas sim à esquerda radical e reformista.

Não é objetivo deste artigo simplesmente encontrar uma posição econômica/ ideológica para Keynes entre Marx e o experimento soviético, de um lado, e o laissez-faire, do outro - ainda que essa identificação seja muito importante no mundo polarizado que vivemos hoje: "[...] ou você tem laissez-faire ou você tem socialismo. Parece quase impossível, [...] que muitas pessoas imaginem que alguém [Keynes, por exemplo] poderia defender o capitalismo, mas também acreditar que ele nem sempre funciona bem" (Backhouse \& Bateman, 2011, p.157-158). Nosso objetivo é outro. Buscamos identificar uma posição peculiar de Keynes a partir de análise detalhada da sua relação com a esquerda comunista para concluir que suas ideias/utopia podem ser absorvidas pela esquerda reformista e radical. Nos periódicos tradicionais da literatura sobre Keynes não encontramos artigos sobre essa temática.

$\mathrm{O}$ artigo está dividido em mais quatro seções, além das considerações finais. $\mathrm{Na}$ próxima, "O Capital e a economia empresarial”, mostram-se as convergências e divergências de Keynes em relação às ideias de Marx. Na seção "A luta de classes e o comunismo", identificam-se as críticas de Keynes aos métodos sugeridos por Marx para alcançar uma nova sociedade. Na seção "A revolução russa e os bolcheviques”, revelam-se o entusiasmo de Keynes com a revolução russa de 1917 e com os seus resultados esperados e futuros; e sua decepção com a falta de liberdade e perseguição que emergiram naquele regime. Na seção "Keynes e a sua utopia comunista", identifica-se que ele vislumbrava resultados para o experimento comunista soviético que compunham os seus ideais: pleno emprego, renda satisfatória para os trabalhadores, significativos investimentos públicos e planejamento econômico, em um ambiente de liberalismo político.

\section{O CAPITAL E A ECONOMIA EMPRESARIAL}

Em 1933, nos escritos preparatórios da sua Teoria Geral, Keynes fez menção a uma passagem d'O Capital ao utilizar os esquemas de Karl Marx conhecidos como C - M - C e M - C - M', onde C representa mercadoria (commodity) e M denota moeda (money) - e M'é maior que M. 
Marx utilizou esses esquemas para explicar a circulação da moeda e a circulação e a produção de mercadorias na economia capitalista. No esquema $\mathrm{C}-\mathrm{M}-\mathrm{C}$, segundo Marx, estaria representada a venda na fase C - M (commodity é transformada em moeda) e a compra ocorreria na fase M - C (moeda é transformada em commodity). Nesse esquema, a moeda está fazendo circular mercadorias em movimentos sucessivos de venda, compra e consumo. Nas palavras de Marx:

$\mathrm{O}$ circuito $\mathrm{C}-\mathrm{M}-\mathrm{C}$ tem por ponto de partida uma mercadoria e por ponto final outra mercadoria que sai da circulação e entra na esfera do consumo. Seu objetivo final é, portanto, o consumo, satisfação de necessidades [...].(Marx, 1984, p.169)

Para reforçar elementos de sua teoria, Keynes fez referência às duas formas de circulação da moeda descritas por Marx dando destaque para o esquema M - C - M'. Keynes utilizou tal esquema para fazer uma distinção crucial que compôs sua teoria econômica. Marx distinguiu os dois esquemas dizendo que no primeiro ( $\mathrm{C}$ $-\mathrm{M}-\mathrm{C}$ ) a moeda era simplesmente moeda, mas no segundo $\left(\mathrm{M}-\mathrm{C}-\mathrm{M}^{\prime}\right)$, a moeda era capital. Nesse último, para Keynes, a moeda alimentaria uma firma na condição de input e o objetivo seria obter mais moeda como output. Inicialmente a moeda compraria insumos e horas de trabalho para realizar a produção. Posteriormente, tal produção seria vendida e, então, M' seria obtida.

Foi exatamente essa diferença (entre os dois esquemas) que Keynes fez referência afirmando que era uma "[...] observação significativa feita por Karl Marx" (Keynes, 2013a, p.81). De forma precisa, pode-se dizer que a distinção que importava para Keynes era aquela entre a Economia Clássica ${ }^{2}$ e a economia empresarial por ele descrita como ponto de partida para a elaboração da sua teoria econômica. Para os clássicos, o que importavam eram quantidades de mercadorias; para Keynes, eram quantidades de moeda. Em uma economia empresarial, o capitalista somente iniciaria a produção se ele esperasse obter ao final, isto é, após a venda do que produziu, mais moeda do que aquela quantidade que gastou para iniciar tal produção.

Rejeitando o esquema C - M - C como sendo representativo do mundo dos negócios, Keynes afirmou:

Esse pode ser o ponto de vista do consumidor privado. Mas não é a atitude dos negócios, que é um caso de $\mathrm{M}-\mathrm{C}-\mathrm{M}$ ', isto é, de se partir da moeda para a mercadoria (ou esforço) com o objetivo de obter mais moeda. (Keynes, 2013a, p.81)

\footnotetext{
2 Para Keynes, a Economia Clássica é aquela que pressupõe que os fatores de produção desejam e recebem como recompensa de seus esforços produtivos uma parcela predeterminada da produção agregada podendo tal remuneração ser em mercadorias ou em algo (moeda) que seja transformado na quantidade predeterminada. Neste contexto, observa-se a validade da Lei de Say e da Teoria Quantitativa da Moeda.
} 
A operação de todas as firmas conformando uma economia empresarial poderia, portanto, na visão de Keynes, ser representada pelo esquema $\mathrm{M}-\mathrm{C}-\mathrm{M}^{\prime}$. $^{3}$ Embora a observação de Keynes sobre a referida passagem de O Capital tenha sido considerada por ele bastante ilustrativa, deixou um alerta para mostrar sua distância em relação às ideias de Marx que são (quase todas) consequência do esquema $\mathrm{M}-\mathrm{C}-\mathrm{M}$ '. Keynes disse: “[...]embora o uso subsequente para o qual ele [Marx] colocou essa observação fosse altamente ilógico” (Keynes, 2013a, p.81 grifos nossos). Logo em seguida àquela observação elogiosa d'O Capital, Keynes foi bastante crítico e afirmou:

Marx, no entanto, estava se aproximando da verdade parcial quando ele acrescentou que o excesso contínuo de M' seria inevitavelmente interrompido por uma série de crises, gradualmente crescentes em intensidade, ou falência empresarial e subemprego, durante a qual, presumivelmente, M deve estar em excesso. (Keynes, 2013a, p.82)

Com essas palavras, Keynes resumiu a ideia central de Marx que era fruto do seu esquema M - C - M'. Para Keynes, tal esquema era ilustrativo do funcionamento do capitalismo na forma de uma economia empresarial. Para Marx, era isso, mas era muito mais. A diferença entre M e M' foi o que Marx chamou de mais-valia ${ }^{4}$ - que era a fonte da exploração do trabalhador por parte do capitalista.

$\mathrm{Na}$ visão de Marx, a extração de mais-valia seria a semente da insatisfação do proletário, ${ }^{5}$ era o motivo básico para a organização dos trabalhadores para a luta de classes e, ainda, a base para a conformação da estratégia de substituição (inevitável) do capitalismo pelo comunismo. ${ }^{6}$

Então, Keynes interpretou que, segundo Marx, a dinâmica capitalista, de crise

\footnotetext{
${ }^{3}$ Para Keynes, a moeda é um fim e não um meio ( $\left.\mathrm{M}-\mathrm{C}-\mathrm{M}^{\prime}\right)$. Obter mais moeda $\left(\mathrm{M}^{\prime}>\mathrm{M}\right)$ seria necessário porque isso significaria aumentar o comando sobre a riqueza existente. A forma monetária seria necessária porque a moeda é o ativo mais líquido da economia propiciando mais segurança diante da incerteza. Além disso, a moeda ofereceria ao seu detentor flexibilidade para refazer planos (ver Cardim de Carvalho, 2015, pp.1-12).

4 “Esse acréscimo ou o excedente sobre o valor primitivo chamo de mais-valia (valor excedente). O valor originalmente antecipado não só se mantém na circulação, mas nela altera a própria magnitude, acrescenta uma mais-valia, valoriza-se. E este movimento transforma-o em capital” (Marx, 1984, p.170).

${ }^{5}$ Para Marx, a existência da mais-valia coincide com a existência do proletariado e da burguesia em lados opostos. Nas suas palavras, juntamente com Engels: "O proletariado passa por diferentes etapas de desenvolvimento. A sua luta contra a burguesia começa com a sua existência” (Marx \& Engels, 1982, p.114).

6 "Com o desenvolvimento da grande indústria é retirada debaixo dos pés da burguesia a própria base sobre que ela produz e se apropria de produtos. Ela produz, antes do mais, o seu próprio coveiro. A sua queda e a vitória do proletariado são igualmente inevitáveis.” (Marx \& Engels, 1982, p.117) A inevitabilidade indicada por Marx \& Engels dependeria de o proletariado estar amplamente e bem organizado para luta de classes e, ademais, de se sair vitorioso. Portanto, em sentido estrito, tal inevitabilidade pode ser amenizada (ou descartada).
} 
em crise, conduzida pela luta de classes, poderia levar ao comunismo. ${ }^{7}$ Keynes usou, em seus Essays in Persuasion, (no capítulo A short view of Russia) 8 de 1931, “[...] o termo 'comunismo' para significar a nova ordem [...]” (Keynes, 2013b, p.258n). Essa caminhada que partia da extração de mais-valia (para Marx) ou da dinâmica de uma economia empresarial (segundo Keynes) que poderia ter como ponto final o comunismo era o uso que Keynes considerou "altamente ilógico" da importante observação que Marx fez em O Capital.

O uso considerado, por Keynes, "altamente ilógico" não apareceu em $O$ Capital (de 1867), mas sim no Manifesto do Partido Comunista (de 1848). Para Marx, a luta de classes sempre existiu, mesmo antes do capitalismo. A diferença é que no capitalismo, a luta ocorreria entre a burguesia e o proletariado com uma nova forma de exploração (Marx \& Engels, 1982, p.107), ou seja, a extração de mais-valia.

Nas obras de Keynes, somente foi deixado um registro de tratamento de tema específico d'O Capital. São os esquemas já mencionados. Há uma outra menção, embora menos direta, mas também muito importante. No ensaio biográfico que Keynes escreveu sobre Thomas Malthus, ${ }^{9}$ embora reconhecendo que "não era um bom estudioso marxista [...]”, ele argumentou que Marx e Malthus sustentaram "[...] que a demanda efetiva poderia falhar em uma sociedade capitalista [...]" (Keynes, 2013d, p.71) - o que era mais um ponto de encontro entre Keynes e Marx.

A despeito da escassez de elementos tratados por Keynes presentes em O Capital, ele atacou com palavras ríspidas essa obra de Marx, ainda que enfatizando a sua enorme influência. Em carta de dezembro de 1934 a Bernard Shaw, ele sentenciou:

Meus sentimentos sobre O Capital são os mesmos que os meus sentimentos sobre o Alcorão. [[...]] Sua controvérsia acadêmica, sombria e desa-

\footnotetext{
${ }^{7}$ A transição do capitalismo ao comunismo, entremeadas por crises, rotuladas de crises de superprodução, foi assim descrita por Marx \& Engels: “[...] as crises comerciais que, sua recorrência periódica, põem em causa, cada vez mais ameaçadoras, a existência de toda a sociedade burguesa. [...] E como a burguesia supera as crises? Por um lado, pela destruição forçada de uma massa de forças produtivas; por outro lado, pela conquista de novos mercados e pela exploração mais profunda dos velhos mercados. Como, então? Preparando crises mais generalizadas e mais graves, e reduzindo os meios para prevenir novas crises. As armas que a burguesia derrubou o feudalismo viram-se agora contra a própria burguesia. Mas a burguesia não forjou apenas as armas que lhe trazem a morte; também gerou os homens que vão usar essas armas - os operários modernos, os proletários" (Marx \& Engels, 1982, p.112). Keynes não avaliava que o capitalismo necessariamente tropeçaria em crises, mas sim que o capitalismo planejado e regulado seria eficiente. "Ele poderia, portanto, repudiar totalmente o marxismo, que se baseava na crença de que, uma vez que o capitalismo tivesse cumprido sua tarefa, seria possível criar uma sociedade socialista na qual o capitalismo tivesse sido abandonado" (Backhouse \& Bateman, 2011, p.64).

${ }^{8}$ Keynes escreveu três artigos sobre a Rússia quando ele e sua esposa Lydia Lopokova visitaram aquele país em 1925 logo após o casamento. Os artigos apareceram pela primeira vez no Nation and Athenaeum, de outubro de 1925. O conteúdo desses artigos reapareceu nos seus Essays in Persuasion.

${ }^{9}$ Keynes tinha como um de seus gêneros literários favoritos a descrição do retrato psicológico, biográfico e de ideias de personalidades, entre elas, Malthus, Leon Trotsky, Albert Einstein, Isaac Newton e Alfred Marshall. Ele publicou, em 1933, os seus Essays in Biography (ver Keynes, 2013d).
} 
tualizada, parece tão extraordinariamente inadequada [...] Você acredita tanto em O Capital quanto no Alcorão? Ou apenas no O Capital? Mas seja qual for o valor sociológico deste último, tenho certeza de que seu valor econômico contemporâneo [...] é nulo. (Keynes, 2013c, p.38)

O olhar que Keynes estabeleceu sobre as ideias de Marx parece estar baseado na leitura do livro I d'O Capital e no Manifesto do Partido Comunista. Contudo, essa não é uma afirmação que possa ser feita com plena segurança. Um ponto é certo: Keynes reconheceu que não era um bom estudioso das obras de Marx. Entretanto, isso não reduz a importância da identificação da visão de Keynes sobre Marx. Essa é apenas uma observação que busca dar precisão ao seu olhar. Cabe ser destacado que o estudo aprofundado do marxismo à época de Keynes, além de não ser o seu foco, era muito restrito a grupos localizados na Áustria, Alemanha e na Rússia soviética (ver Cerqueira, 2015, pp.827-832). Àquela época, em que movimentos socialistas se espalhavam pela Europa, as ideias mais difundidas que eram atribuídas a Marx parecem ser aquelas que Keynes mais absorveu - inclusive o marxismo associado ao leninismo e ao stalinismo. ${ }^{10}$

\section{A LUTA DE CLASSES E O COMUNISMO}

Sobre a luta de classes, que era o caminho indicado por Marx que poderia ligar a existência da mais-valia à sua supressão, Keynes lançou duras palavras. No seu conhecido artigo Am I a liberal?, de 1925, Keynes tentando responder por que não se filiaria ao Partido Trabalhista britânico, escreveu:

Para começar, é um partido de classe, e a classe não é a minha classe. Se eu vou perseguir interesses de partes específicas, vou perseguir os meus. [...] Eu posso estar influenciado pelo que parece ser justiça e bom senso; mas a luta de classes me encontrará do lado da burguesia culta. (Keynes, 2013b, p.297)

Essas expressões de Keynes, aos olhos de um observador obtuso, são palavras que o colocariam do lado da burguesia opressora e exploradora. Contudo, a atitude de Keynes pode ser interpretada de outra forma: não como uma posição classista, mas sim como uma posição de um iluminista.

Em paralelo àquela afirmação (“do lado da burguesia[...]”) tão supostamente nítida, Keynes desenvolveu a ideia que a questão fundamental para ele seriam temas econômicos que não poderiam ser tratados pela massa trabalhadora que tinha influência no Partido Trabalhista. Disse ele:

\footnotetext{
${ }^{10}$ Detalhes sobre o movimento que ocorreu na Rússia nos anos 1930 de divulgação de uma conexão entre as ideias de Marx com o leninismo e o stalinismo podem ser encontrados em Cerqueira (2015, p.830).
} 
Acredito que, no futuro, mais do que nunca, as questões sobre a estrutura econômica da sociedade serão de longe o mais importante dos temas políticos. Acredito que a solução certa envolverá grupos intelectuais e científicos que devem estar acima das possibilidades da vasta massa de eleitores mais ou menos iliterata. (Keynes, 2013b, p.295)

Ele defendeu a ideia que uma cúpula de dirigentes cultos na direção de um partido poderia tratar de problemas econômicos sofisticados que deveriam ser balizados por "justiça e bom senso". Keynes não disse que estaria do lado burguesia no sentido indicado por Marx, ou seja, ao lado da burguesia opressora e exploradora, mas sim "do lado da burguesia culta", isto é, bem formada, pensante, intelectualizada. Em defesa de uma cúpula partidária de iluminados, Keynes criticou o Partido Liberal e o Trabalhista britânicos:

Tradicionalmente, a administração do Partido Liberal era também suficientemente autocrática [tal como a do Partido Conservador]. Recentemente, tem ocorrido movimentos mal direcionados no caminho da democratização de detalhes do programa do partido. [...] O Partido Trabalhista, por outro lado, está em uma posição muito mais fraca. Eu não acredito que os grupos intelectuais do partido exerçam controle adequado [...] (Keynes, 2013b, p.295-296)

Entre os três partidos políticos, a conclusão de Keynes foi a seguinte: “[...] o Partido Conservador está na melhor posição. A cúpula do partido pode quase ditar os detalhes e a técnica da política" (Keynes, 2013b, p.295). Portanto, a posição de Keynes é bem mais peculiar. Ele disse que estaria do lado da burguesia culta e não estaria em um partido [o Trabalhista] que por questões eleitorais tinha que sofrer a influência dos trabalhadores e dos sindicatos que eram, na visão de um iluminista, ignorantes em relação a problemas econômicos sofisticados. A atitude de Keynes pode ser definida como a de um intelectual elitista ou iluminista disposto a resolver os problemas da sociedade e não apenas de uma de suas partes (a classe trabalhadora).

A posição de Keynes descritiva da luta classes proposta por Marx foi apresentada, no ano de 1934, em carta ao editor do New Statesman and Nation da seguinte forma:

A facção da luta de classes acredita que é bem conhecido o que deve ser feito; que nós estamos divididos entre os pobres e os bons que gostariam de fazê-lo, e os ricos e iníquos que, por razões de interesse próprio, desejam evitá-lo, que os iníquos têm poder; e que é necessária uma revolução para depô-los de suas posições. Eu vejo o problema de outra forma. Eu acho extremamente difícil saber o que deve ser feito, e extremamente difícil para aqueles que sabem (ou pensam que sabem) persuadir os outros de que estão certos [...]. (Keynes, 2013c, p.36) 
Quando Keynes apresentou tais posições, não disse que estaria do lado dos ricos e iníquos. Mas sim que o problema deveria ser visto de outra forma. Keynes não avaliava que tudo deveria ser visto por uma ótica binária (comunista ou capitalista), tal como era a visão dos marxistas. Considerava que era uma decorrência dessa visão binária que a luta de classes poderia levar o proletariado pela via da revolução violenta e abrupta ao comunismo.

Em contraste com o entendimento de marxistas, Keynes confiava na força da persuasão associada às boas ideias e teorias. Keynes não admirava o uso da força proposta pela luta de classes, nem acreditava em mudanças revolucionárias abruptas. São palavras de Keynes: "O próximo movimento é com a cabeça e os punhos devem esperar" e "A força não resolveria nada" (Keynes, 2013d, p.67). ${ }^{11}$ Ele acreditava na força da persuasão e da luta de ideias: "O problema hoje é primeiro elaborar bons conselhos e depois convencer os bem-intencionados de que sejam bons." (Keynes, 2013c, p.34). Em 1934, comentando a posição de Bernard Shaw, ${ }^{12}$ Keynes disse que confiava na força da persuasão, inclusive para isolar os capitalistas egoístas (autointeressados):

Suspeito que a preferência de Bernard Shaw por tiranos é devida principalmente a ele estar impressionado com as dificuldades da persuasão. É mais fácil persuadir um tirano a adotar sua política do que persuadir a democracia. Eu concordo com ele. Mas não é o autointeresse que dificulta a democracia para persuadir. Neste país, daqui em diante o poder normalmente estará com a esquerda. O Partido Trabalhista sempre terá uma maioria [...]. Se, e quando, e na medida em que eles são capazes de persuadir pessoas razoáveis e desinteressadas de que estão certos, o poder dos capitalistas autointeressados de se colocar em seu caminho é insignificante. (Keynes, 2013c, p.36)

Keynes valorizava a intelligentsia, isto é, uma vanguarda de intelectuais. Além disso, defendia a liberdade como uma questão de princípio, ou seja, como valor universal (pois somente assim a vanguarda de intelectuais poderia agir). A liberdade não poderia jamais ser extinta em qualquer lugar ou em qualquer tempo. ${ }^{13}$

\footnotetext{
${ }^{11}$ As citações dessa frase são do ensaio de Keynes sobre Leon Trotsky que compõe os seus Essays in Biography.

${ }^{12}$ A Rússia e as ideias de Marx ocuparam Keynes no final do ano de 1934. O New Statesman publicou uma entrevista de Josef Stálin feita por H. G. Wells. Bernard Shaw comentou a entrevista no veículo e Keynes fez uma réplica.

13 “Ele [Keynes] era um liberal clássico em sua política, sendo tão apegado à liberdade individual quanto o libertário mais ardente, que ao longo de sua vida repudiou o socialismo [...]. No entanto, ele permaneceu firmemente à esquerda, procurando usar os recursos do Estado para criar uma sociedade melhor" (Backhouse \& Bateman, 2011, p.148). Sobre a posição desses dois autores, é nítido que Keynes foi um libertário. Contudo, deve-se tratar com mais cuidado a afirmativa que Keynes sempre se manteve à esquerda. Como argumentado, o posicionamento de Keynes no espectro ideológico não teve grande importância até os anos 1980, até essa década a discussão mais importante era sobre a eficiência das
} 
Em 1939, no New Statesman and Nation, entrevistado pelo editor Kingsley Martin, Keynes mostrou que era um liberal radical e que era um iluminista. Fazendo comentários sobre o Partido Trabalhista britânico, elogiou um de seus ilustres membros, o pró-soviético e considerado de ultraesquerda, Stafford Cripps: "Sou a favor de Sir Stafford Cripps e gostaria de me juntar ao seu movimento se ele for bem-sucedido em lançá-lo[...]" (Keynes, 2013f, p.495). ${ }^{14}$ Além disso, Keynes condenou as restrições do Partido Trabalhista às ações dos seus jovens comunistas: "Quão tolo, também, em condenar o Left Book Club! Certamente é um dos melhores e mais vivos movimentos do nosso tempo" (Keynes, 2013f, p.496). ${ }^{15}$ Sobre os jovens comunistas do Partido Trabalhista, Keynes disse ainda: “[...] na maturidade deles reside o futuro [...]" (Keynes, 2013f, p.496).

A restrição à liberdade e a subvalorização da intelligentsia colocaram Keynes em confronto com o comunismo, ${ }^{16}$ tal como ele o via na Rússia nos anos 1920. Para Keynes, os fins não poderiam justificar os meios. O liberalismo político era um princípio. Em carta ao editor do New Statesman and Nation, no ano de 1934, Keynes afirmou:

Os marxistas estão prontos para sacrificar as liberdades políticas dos indivíduos com o objetivo de mudar a ordem econômica existente. Então, são fascistas e nazistas. [...] Meu objetivo é a reforma econômica pelos métodos do liberalismo político. (Keynes, 2013c, p.28-29)

Ele considerava o comunismo "[...] um credo que não se importa com o quanto destrói a liberdade e a segurança da vida cotidiana, que usa deliberadamente as armas da perseguição [...]" (Keynes, 2013b, p.258). Então, no capítulo A short view of Russia de seus Essays in Persuasion, Keynes questionou:

Como posso adotar um credo que, preferindo a lama ao peixe, exalta o proletariado grosseiro acima dos burgueses e da intelligentsia que, com

políticas econômicas sugeridas por Keynes. E, ademais, é necessário qualificar a qual esquerda as ideias de Keynes podem aderir, tal como é argumentado neste artigo.

${ }^{14}$ Stafford Cripps foi expulso do Partido Trabalhista por defender uma frente dos trabalhistas com os comunistas e socialistas para combater o nazismo. Esse foi o movimento que Keynes se referiu com simpatia, sugerindo inclusive a sua própria participação. Cripps foi reintegrado ao Partido e se tornou embaixador na União Soviética durante a II Guerra Mundial.

15 "O Left Book Club foi originalmente fundado em 1936 para popularizar as ideias da esquerda e contra a ascensão do fascismo. Por volta de 1939, havia 57.000 membros operando 1.200 grupos de leitura" (extraído do site https://www.leftbookclub.com). O Club tem funcionamento regular nos dias de hoje. Seu lema é "Leia, debata e organize" e "Ideias mudam o mundo. Compartilhe-as".

${ }^{16}$ Tal rotulação (comunismo) pode sofrer objeções que entenderiam que aquela organização política e econômica não poderia ser dessa forma batizada. Existiriam inúmeros rótulos para diferentes fases. Para detalhes sobre tais taxonomias, ver Albuquerque (2005, pp.254-263). Para nosso propósito, o mais importante não são rótulos, mas sim que Keynes via um novo experimento florescendo e sobre ele demostrava interesse, independentemente de como poderia ser batizado. 
todos os defeitos, são a qualidade da vida e seguramente as sementes de todo avanço humano? (Keynes, 2013b, p.258)

Embora Keynes repudiasse os métodos do comunismo, reconheceu que esse regime poderia trazer algo inovador: o fim do "amor pelo dinheiro" (love of money). ${ }^{17}$ Keynes considerava legítima a procura incessante pelo dinheiro resultante da atividade profissional de um indivíduo. $\mathrm{O}$ indivíduo enriqueceria visando à realização da “[...] prosperidade e poupança, e a obtenção de segurança financeira e independência para si mesmo e para a família” (Keynes, 2013b, p.260).

Apesar de reconhecer a legitimidade da busca pelo dinheiro, Keynes via tal caminho com reservas, enxergava nessa via um certo perigo ${ }^{18}$ ou mesmo uma inutilidade se tudo o que seria almejado pelo enriquecimento fosse atendido por toda a sociedade (inclusive o setor público) apoiando cada indivíduo - além do mais, o enriquecimento era considerado difícil de ser alcançado no comunismo (Keynes, 2013b, p.260). A abolição da busca pelo enriquecimento poderia ter a sua semente no comunismo. Nas palavras de Keynes,

[...] [o comunismo] tenta construir uma estrutura de sociedade na qual os motivos pecuniários como influenciando a ação terão uma importância relativa alterada, na qual os reconhecimentos sociais serão distribuídos de maneira diferente, e onde o comportamento, que anteriormente era normal e respeitável, deixa de ser uma coisa ou outra. (Keynes, 2013b, p.259-260)

Keynes concluiu que com o amadurecimento do comunismo, onde gerações de indivíduos nascessem em uma estrutura de sociedade diferenciada, os jovens não teriam a motivação pecuniária pelo enriquecimento, disse ele: “[...] na Rússia do futuro, pretende-se que a carreira de fazer dinheiro [money-making], como tal, simplesmente não surja para um jovem respeitável como uma oportunidade possível [...]” (Keynes, 2013b, 260). No comunismo, haveria “[...] uma mudança real na atitude predominante em relação ao dinheiro[...]” (Keynes, 2013b, p.261) e que,

\footnotetext{
${ }^{17}$ Numa sociedade onde todas as dificuldades materiais tivessem sido superadas, Keynes explicitou em seu artigo Economic possibilities for our grandchildren (de 1930) que: "O amor pelo dinheiro como uma posse - distinto do amor pelo dinheiro como um meio para os prazeres e realidades da vida - será reconhecido como aquilo que é, uma morbidade repugnante, uma daquelas propensões semicriminais e semipatológicas que se entrega com arrepio aos especialistas em doença mental". (Keynes, 2013b, p.329).

18 Para Keynes, a busca pelo enriquecimento poderia ser uma válvula de realizações pessoais, mas poderia levar a uma condição que favoreceria a efetivação da dominação em uma sociedade capitalista: “[...] perigosas inclinações humanas podem ser direcionadas para canais comparativamente inofensivos pela existência de oportunidades para ganhar dinheiro e riqueza privada, que, se não puderem ser satisfeitas dessa maneira, podem encontrar sua saída na crueldade, na busca imprudente de poder e autoridade pessoal, e em outras formas de autoengrandecimento. É melhor que um homem possa tiranizar seu saldo bancário que tiranizar seus concidadãos; embora o primeiro caso seja algumas vezes um meio de levar ao segundo, em certos casos é pelo menos uma alternativa” (Keynes, 1973, p.374).
} 
portanto, “[...] ganhar dinheiro e acumular dinheiro não pode entrar nos cálculos da vida de um homem racional que aceita a regra soviética da mesma forma que entra nos nossos [cálculos]" (Keynes, 2013b, p.261).

Há ainda uma importante referência de Keynes ao comunismo feito nos escritos preparatórios da Teoria Geral. Em sua tentativa de mostrar que somente em situações muito raras haveria pleno emprego, Keynes afirmou que tal situação somente poderia ocorrer de forma permanente em uma sociedade "[...] em que os empregadores fossem igualmente responsáveis pela manutenção de seus homens assim como eles são pela manutenção de suas máquinas, se eles estão utilizando-as ou não" (Keynes, 2013a, p.52). Keynes disse explicitamente que no comunismo isso poderia ocorrer.

\section{A REVOLUÇÃO RUSSA E OS BOLCHEVIQUES}

Durante a I Guerra Mundial, eclodiu a revolução russa, que transcorreu durante o ano de 1917 e culminou com a tomada do poder em novembro pelos bolcheviques. Keynes se mostrou um entusiasta da revolução bolchevique. Nos primeiros meses da revolução, Keynes escreveu à sua mãe dizendo que estava imensamente "alegre e animado" com os acontecimentos da Rússia e que "essa era a única consequência valiosa da Guerra” (Keynes in Skidelsky, 1986, p.327).

A ocorrência da I Guerra Mundial foi para Keynes uma grande decepção. ${ }^{19}$ Primeiramente, por conta do fim da sua esperança de uma "nova civilização" mundial organizada e de paz (Skidelsky, 1999, p.31). Posteriormente, porque considerava que "[...] não valia a pena lutar naquela guerra e que deveriam ser envidados todos os esforços para encerrá-la por meio de uma paz com concessões mútuas" (Skidelsky, 1999, p.32).

Quando Keynes replicou o comentário de Shaw sobre a entrevista de Stálin (já referenciada anteriormente), ele lamentou que devido à Guerra o capitalismo poderia chegar ao fim. Culpou os governantes por terem causado e prolongado a Guerra e por não terem resolvido os problemas que atingiam os trabalhadores - já que considerava o comunismo apenas "[...] um protesto contra o vazio de bem-estar econômico [...]" (Keynes, 2013c, p.35). Keynes avaliava que se a Europa queria se proteger dos bolcheviques deveria oferecer melhores condições de vida aos trabalhadores (Keynes, 2013e, p.436)..$^{20}$

Keynes não poderia ter se oposto à revolução liderada por Lênin. Afinal, a tomada do Palácio de Inverno foi relativamente pacífica. A bandeira da revolução

\footnotetext{
${ }^{19}$ A I Guerra Mundial teve como causa disputas por mercados e territórios e rivalidades históricas, o que certamente decepcionou Keynes.

20 “Ao escrever sobre a Rússia em meados da década de 1920, Keynes opinou que se o capitalismo [...] se tornasse simplesmente [...] [um] capitalismo egoísta ou de autointeresse, as pessoas o achariam moralmente inaceitável e o capitalismo estaria ameaçado" (Backhouse \& Bateman, 2011, p.60).
} 
bolchevique era "paz, pão e terra". Keynes tinha enormes restrições à I Guerra e Lênin propôs a saída da Rússia desse conflito em busca da paz no seu território.

Além disso, Keynes era um defensor do fim da pobreza e da geração de empregos. Lênin, em um país que era agrário, propôs o confisco e a nacionalização de todas as terras dos latifundiários da Rússia para transformá-las em fazendas produtivas (ver Lênin, 1917). Os latifúndios improdutivos estavam para a Rússia assim como fábricas ociosas estariam para a Grã-Bretanha industrializada. "O experimento econômico interessava a ele [...]" (Moggridge, 1993, p.37): Keynes via a Rússia como um laboratório onde seria experimentada uma nova fórmula.

Keynes, em carta à sua mãe no dia 24 de dezembro de 1917 (ver Keynes, 2013e, p.266-267), revelou ser um entusiasta da revolução russa, mas ele indicava que tinha dúvidas sobre o sucesso do novo experimento. Logo após a revolução, ao final do ano de 1917, o governo russo estabeleceu o racionamento de carne e outros alimentos: Keynes passou a temer filas intermináveis, o empobrecimento ou uma desorganização geral da economia. Ele pensava que o algoritmo do governo de aumentar salários enquanto preços e oferta diminuíam faria crescer filas infinitamente (Keynes, 2013e, p.266-267). Na carta, ele explicitou seus sentimentos:

Meus pensamentos de natal são que um prolongamento adicional da guerra, com os acontecimentos já estabelecidos [isto é, a revolução russa], provavelmente significa[rá] o desaparecimento da ordem social que temos conhecido até agora. [...] O que me assusta mais é a perspectiva do empobrecimento geral. [...] Bem, o único caminho aberto para mim é ser bolchevique otimista; [...] os nossos governantes são tão incompetentes, como eles são loucos e incrédulos, [assim] uma era particular de um tipo específico de civilização está quase acabando. (Keynes, 2013e, p.266-267)

Após alguns anos da revolução, Keynes ainda mantinha simpatia pelo processo que se desenvolvia na Rússia. No ano de 1922, ele foi contratado como correspondente para escrever uma série de artigos para o Manchester Guardian sobre a Conferência de Gênova. O propósito da Conferência era restabelecer a confiança entre as nações após o evento da I Guerra (ver Moggridge in Keynes, 2013g, p.354).

A Rússia apareceu em vários artigos de Keynes já que eram temas internacionais: as dívidas contraídas pelos governos czaristas, as dívidas feitas juntos aos Aliados durante a I Guerra e a discussão sobre compensação ou restituição diante do confisco das propriedades de estrangeiros durante o governo bolchevique.

Cabem destaques para os artigos Rubbish about Milliards e The financial system of the Bolsheviks. No primeiro, Keynes enfatizou que a revolução libertou os russos "[...] de muitas coisas, dentre elas, das imensas obrigações contraídas junto ao exterior pelo velho regime [que eram utilizadas] para seus próprios fins" (Keynes, 2013g, p.389). No segundo, Keynes demostrou surpresa e satisfação com os rumos da organização econômica em curso na Rússia. Ele trocou ideias com a 
delegação russa presente em Gênova e concluiu que estava em curso uma rápida e plena superação[...]

[...] do caos original e do lodo primitivo que é provável que seja nossa ideia da Rússia Soviética. Uma experiência extraordinária de socialismo está em curso de desenvolvimento. Eu acho que podem existir sólidas fundações sobre as quais [se pode] construir uma ponte. (Keynes, 2013g, p.408, grifos nossos).

Keynes visitou a Rússia pela primeira vez em 1925. Lênin já havia falecido. Ele tinha respeito por Lênin. É muito conhecida a passagem em que Keynes, tratando do problema da inflação em 1919, afirmou: "Lênin seguramente estava certo. Não há meios mais sutis, nem mais seguros de derrubar a base existente da sociedade do que desmoralizar a moeda" (Keynes, 2013h, p.149).

Ademais, Keynes destacou, ainda no seu A short view of Russia, elogios a Lênin, sua rejeição ao regime russo e sua admiração pelos avanços estruturais e econômicos. De forma elogiosa, Lênin foi considerado um político prático, que adotava o método da tentativa e erro sem limites: "Ninguém jamais foi mais abertamente experimentalista do que Lênin [...]" (Keynes, 2013b, p.262). Keynes enviou, via Georgy Chicherin, ${ }^{21}$ um pedido a Lênin em 1922 convidando-o para escrever um breve prefácio para o suplemento Reconstruction in Europe na parte referente à Rússia que foi publicado no Manchester Guardian (Moggridge in Keynes, 2013g, p.402-403). Lênin não chegou a responder, já estava gravemente doente desde 1921.

As impressões de Keynes sobre a Rússia eram pendulares. Mas existia uma clara tendência de distanciamento daquele regime. A rejeição de Keynes era específica: estava no campo da destruição da possibilidade de o comunismo ser um regime com liberalismo político. Ele passou a considerar o comunismo como uma religião e disse: "Como outras novas religiões, parece retirar a cor, a alegria e a liberdade da vida cotidiana e oferecer um substituto desbotado nas faces pálidas de seus devotos" (Keynes, 2013b, p.256-257).

Em relação à economia russa, Keynes demostrou um otimismo contido. Via um certo crescimento do comércio privado, do capital estatal e um governo que honraria suas dívidas com financiadores das suas importações. Via também um proletariado urbano recebendo bons salários, um elevado desemprego nas cidades e os camponeses satisfeitos por terem a sua própria terra para trabalhar e produzir. Considerava que o sistema ainda tinha um baixo nível de eficiência, mas que funcionava e continha elementos de continuidade (ver Keynes, 2013b, pp.253-271). Observou, contudo, com muito otimismo os grandes investimentos estatais:

Alguns dos esquemas grandiosos do novo regime estão começando a tomar forma. Em breve, Leningrado será abastecido com energia e luz de

\footnotetext{
${ }^{21}$ A Rússia fez parte da Conferência de Gênova representada por delegação chefiada por seu ministro das Relações Exteriores, Georgy Chicherin.
} 
uma das maiores e mais modernas estações geradoras do mundo. (Keynes, 2013b, p.266)

A partir de 1928, Stálin estabeleceu os Planos Quinquenais de planejamento estatal com o objetivo de desenvolver a agricultura, a indústria e a geração e distribuição de energia elétrica. Keynes valorizava muito o planejamento da economia feito a partir do Estado. Destacou, contudo, que o planejamento não era parte da economia do comunismo. Afinal, o fascismo também praticava o planejamento (Keynes, 2013f, p.85) Keynes avaliava, entretanto, que não seria necessário abrir mão da democracia para realizar o planejamento.

Nos escritos preparatórios da Teoria Geral (durante o ano de 1932), Keynes disse que os Planos Quinquenais eram um exemplo de organização econômica que faz crescer a produção até o seu ponto ótimo sem trazer para dentro do sistema forças “[...] que tendem a reduzir a produção antes que esse ponto ótimo seja alcançado" (Keynes, 2013i, p.389).

Keynes concordou com H. G. Wells que ao entrevistar Stálin, em 1934, sugeriu que o planejamento pudesse ser feito por técnicos e engenheiros. Mas foi contestado por Stálin que disse que a intelligentsia técnica não poderia jogar um "papel histórico independente" (Stálin in Skidelsky, 1994, p.518).

Keynes, em programa de rádio, transmitido em 14 de março de 1932, discordou das ideias de Stálin ao afirmar que desejava o melhor do comunismo, ou seja, o planejamento, e o melhor da democracia, ou seja, a liberdade individual:

Não pode ser um preço necessário pagar pelos benefícios do planejamento estatal que também tenhamos que sofrer as outras afrontas ao indivíduo que parecem ser inseparáveis de um estado bolchevique ou fascista? Para mim, não vejo por que isso precisa ser assim. Pelo menos eu gostaria de tentar se não seria possível aproveitar as vantagens de ambos os mundos. (Keynes, 2013f, p.91)

De fato, a União Soviética dirigida por Stálin seguiu o caminho da extinção das liberdades. Essa conformação causou horror em Keynes que escreveu uma carta (em 1937) para Kingsley Martin dizendo:

[...] Stálin está envolvido em uma destruição sistemática do antigo Partido Comunista. [...] 2.800.000 membros do Partido Comunista, algo como $25 \%$, foram executados, presos, exilados ou demitidos de seus cargos nos últimos meses. [...] A posição de Stálin logo se tornará indistinguível da de outros ditadores. (Keynes, 2013c, p.72)

Segundo Keynes, "Stálin eliminou toda reflexão crítica e independente, mesmo quando tem uma visão geral simpática. Ele produziu um ambiente em que os processos reflexivos estão atrofiados” (Keynes, 2013f, p.246).

Apesar de Keynes ter destacado as atrocidades do regime liderado por Stálin, ele já apontava a existência de práticas tiranas desde o período leninista. Após a 
sua primeira viagem à Rússia, sua imagem sobre o regime político era decepcionante. Contudo, ele sempre viu com algum otimismo as possibilidades daquele país vir a alcançar objetivos que compunham a sua utopia. Apesar de todas as contrariedades, Keynes deixou a seguinte mensagem no último parágrafo do seu $A$ short view of Russia:

[...] eu gostaria de dar à Rússia sua chance; para ajudar e não para dificultar [...] se eu fosse russo, contribuiria com minha quota de atividade para a Rússia soviética [...] Eu deveria detestar as ações dos novos tiranos não menos do que as dos antigos. [Contudo] da crueldade e estupidez da Velha Rússia, nada poderia emergir, mas, sob a crueldade e estupidez da Nova Rússia alguma partícula do ideal pode estar escondida. (Keynes, 2013b, p.271)

Em 1945, Keynes reconheceu que a Rússia foi bem-sucedida na superação da fome e na sua reconstrução em curto espaço de tempo, embora mais uma vez tenha destacado sua discordância em relação aos métodos de governo utilizados (Keynes, 2013k, p.275-276).

\section{KEYNES E A SUA UTOPIA COMUNISTA}

Keynes nunca foi um comunista. Quanto à permanência do regime soviético sempre foi um agnóstico: não tratou do assunto e muito menos fazia campanha pela sua consolidação ou destruição. Olhava para a União Soviética como um cientista observa as reações de um novo experimento. Os olhos críticos e ácidos de Keynes estavam mais voltados para os métodos e não para a emergência do novo experimento. Keynes simplesmente buscou analisar o novo experimento e desejava que seus resultados fossem positivos (de acordo com suas ideias).

Keynes não opôs o capitalismo ao comunismo. Keynes fazia oposição entre tirania (perseguição de indivíduos, embotamento de consciências) e democracia (liberdade individual e política). Esse era o ponto central de crítica e desgosto em relação ao regime soviético. Keynes acreditava que o desenvolvimento científico e a difusão do conhecimento deveriam ser os meios para que o bem-estar pudesse ser alcançado (e mantido) para todos. ${ }^{22}$ Para ele, em uma sociedade com um governo tirano, a possibilidade de reflexão estaria ceifada. A livre difusão de conhecimento e ideias inexistiria. Para Keynes, a democracia e o bem-estar, ambos, eram objetivos finais. A sua sociedade ideal deveria conter bem-estar econômico e bem-estar político.

\footnotetext{
${ }^{22}$ No seu artigo Economic possibilities for our grandchildren (de 1930), Keynes revelou que acreditava que o pleno desenvolvimento humano no plano material seria atingido se: (i) houvesse controle da população, (ii) não existissem guerras e conflitos civis, (iii) fosse confiada à ciência a solução dos problemas e (iv) ocorresse um ritmo adequado de investimentos (ver Keynes, 2013b, p.331).
} 
Quanto ao O Capital, o livro que considerava a bíblia econômica ${ }^{23}$ da religião comunista, valorizou o seu entendimento de como funciona uma economia empresarial e o seu reconhecimento que esse tipo de economia pode sofrer de insuficiência de demanda. Além dessas duas ideias que auxiliam a compreensão do funcionamento de uma economia empresarial, Keynes acreditava que as ideias de Marx nada podiam oferecer para a solução dos problemas econômicos.

Bernard Shaw era um admirador de O Capital e das demais ideias de Marx e Engels. Ele considerava que a dupla tinha oferecido a solução para os problemas de uma economia capitalista. Keynes contestou Shaw sugerindo que ele sim estaria escrevendo um livro (a Teoria Geral do Emprego, do Juro e da Moeda) que poderia influenciar o mundo. Referindo-se à dupla comunista e ao seu novo livro (a ser lançado no ano seguinte, em 1936), Keynes escreveu a Shaw:

Mas se você me diz que eles descobriram uma pista para o problema econômico, ainda estou chocado. [...] Para entender o meu estado de espírito, entretanto, você tem que saber que eu acredito estar escrevendo um livro de teoria econômica que revolucionará amplamente - não, eu suponho, de uma única vez, mas no curso dos próximos dez anos - a maneira como o mundo pensa sobre os problemas econômicos. Quando minha nova teoria for devidamente assimilada e misturada com a política, sentimentos e paixões, eu não posso prever qual será o resultado final de seus efeitos sobre a ação e os problemas. (Keynes, 2013c, p.42)

Em sua teoria, Keynes não viria a focar sua atenção em uma possível exploração dos trabalhadores por parte dos capitalistas, mas sim no que deveria ser feito para que os capitalistas ofertassem vagas de trabalho para todos os desempregados. O investimento foi considerado por Keynes a variável-chave que faria a economia crescer, gerando novos postos de trabalho e até mesmo o pleno emprego. ${ }^{24}$ Se os empresários não realizassem investimentos, o setor público deveria fazê-lo. Portanto, no regime soviético, o investimento deveria ocorrer através do investimento público e o pleno emprego poderia ser alcançado. ${ }^{25}$

\footnotetext{
${ }^{23}$ Keynes perguntou: "Como posso aceitar uma doutrina que estabelece como sua Bíblia, acima e além da crítica, um livro-texto econômico obsoleto que eu sei que não é só cientificamente errado, mas sem interesse ou aplicação para o mundo moderno?” (Keynes, 2013b, 258).

24 O capítulo 3 da Teoria Geral (Keynes, 1973) demonstrou que os níveis de emprego dependem dos gastos totais da comunidade que, por sua vez, estão sujeitos a variações do nível de investimentos e da propensão média a consumir (que é considerada dada).

${ }^{25}$ A economia do comunismo poderia equivaler para Keynes a uma economia empresarial em que os capitalistas estivessem paralisados. Esse seria o caso de uma economia capitalista em situação de depressão. Nela, o crescimento e a geração de empregos necessitam inexoravelmente dos investimentos públicos - e esse seria também o caso de uma economia no comunismo. Portanto, pode-se inferir que para Keynes o governo deveria regular o volume de investimentos necessários numa economia empresarial em depressão ou numa economia comunista. Para detalhes sobre a necessidade de intervenção governamental em uma economia capitalista em depressão, ver, por exemplo, Keynes (2013f, p.148).
} 
Como corolários, Keynes via na exploração dos trabalhadores através do pagamento de baixos salários um problema de eficiência macroeconômica. Uma reduzida massa salarial proporcionaria uma demanda insuficiente e, portanto, consumaria uma situação de desemprego proporcional ao tamanho do diminuto gasto total. Ademais, baixos salários poderiam refletir também uma situação de concentração de renda, o que para Keynes também poderia ser visto como um outro problema de eficiência macroeconômica. Se a propensão a consumir dos trabalhadores é alta e a dos capitalistas é baixa, uma concentração da renda nas mãos dos capitalistas, nessas circunstâncias, reduziria o efeito multiplicador dos investimentos públicos. ${ }^{26}$ Portanto, diminuiria a potência do governo para gerar novos empregos, alcançar o pleno emprego e mantê-lo.

No seu artigo The dilemma of modern socialism, de 1932, Keynes reconheceu, em consequência, que o controle sobre o volume de investimentos e a distribuição da renda poderiam trazer enormes ganhos para qualquer sociedade:

Estou convencido que aquelas coisas que são urgentemente solicitadas em bases práticas, tais como o controle central do investimento e a distribuição de renda, de modo a fornecer poder de compra para [adquirir] a enorme produção potencial da moderna técnica produtiva, tenderão também a produzir um tipo melhor de sociedade [...]. (Keynes, 2013f, p.36-37)

Luta de classes, violência e ruptura eram palavras que estavam fora do vocabulário e das ideias de Keynes. Em oposição, ele afirmava a persuasão, o gradualismo ${ }^{27}$ e a ocupação de espaços. Confiava na força das boas ideias como motor da própria persuasão. Contudo, não pensava que bastava produzir boas ideias e deixá-las fluir sem (o seu) impulso.

Keynes foi um militante publicista de ideias. Por canais diversos, atuou de forma intensa: trocava cartas/debates de forma organizada, participava de programas de rádio, fazia palestras, elaborou artigos de opinião, acadêmicos e livros e participou de inúmeros grupos temáticos. Além disso, foi professor e organizou seus próprios veículos de comunicação, por exemplo, o New Statesman and Nation..$^{28}$

\footnotetext{
${ }^{26} \mathrm{O}$ multiplicador de gastos de investimentos é função fundamentalmente da propensão média a consumir da comunidade, entre outras variáveis (ver Keynes, 1973, capítulo 10).

${ }^{27}$ Keynes, comentando no seu Economic possibilities for our grandchildren (de 1930) sobre a superação completa das necessidades materiais para todos os seres humanos, afirmou: "[...] tudo acontecerá gradualmente, não como uma catástrofe" (Keynes, 2013b, p.331).

${ }^{28}$ Keynes teve influência decisiva sobre dois veículos: o The Nation and Athenaeum (de 1923 a 1931) e, depois, o New Statesman and Nation (de 1931 até o seu falecimento). Esse último teve duas vertentes de constituição. A primeira foi o New Stasteman criado em 1913 pelo casal fabiano Sidney e Beatrice Webb. A segunda foi a fusão entre o Athenaeum (dedicado a literatura e arte, fundado em 1828) com o liberal The Nation, um veículo que tinha forte influência do Grupo de Bloomsbury. Foi formado, então, o The Nation and Athenaeum. Em 1923, com um grupo de amigos ligado ao partido Liberal, Keynes adquiriu o seu controle. Então, entre 1923 e 1931, o seu editor foi Hubert Henderson (amigo e coautor de Keynes no conhecido panfleto Can Lloyd George do it?, de 1929) e Keynes, o chefe do conselho
} 
A tática de ocupação de espaços e do gradualismo, Keynes talvez tenha absorvido de um dos grupos que era próximo, os socialistas fabianos. Eles pensavam que no lugar de uma ruptura revolucionária deveriam construir uma nova sociedade de forma gradual, ocupando espaços em governos e criando instituições para formar quadros e influenciar toda a sociedade. Fundaram, por exemplo, a London School of Economics (em 1906) e o Partido Trabalhista britânico (em 1900). O lema da Sociedade Fabiana era "educar, agitar e organizar". ${ }^{29}$

Keynes, além de defender o pleno emprego e uma distribuição de renda socialmente justa, também sempre apoiou iniciativas que pudessem promover a igualdade de oportunidades..$^{30} \mathrm{O}$ tripé (pleno emprego, distribuição justa de renda e igualdade de oportunidades) resumia o significado da sua utopia de bem-estar econômico, ao mesmo tempo que retiraria todo o sentido da busca transloucada pelo enriquecimento. Mas a utopia de Keynes também continha o bem-estar político, isto é, a liberdade nas suas formas mais agudas e extensas.

$\mathrm{O}$ resultado final do comunismo desejado por Keynes era uma economia organizada pelos Planos Quinquenais, com pleno emprego, em que os trabalhadores pudessem consumir de forma satisfatória, em que o governo pudesse investir incessantemente e que houvesse igualdade de oportunidades que garantisse segurança permanente da vida de cada um. Isso tudo mergulhado no mais profundo liberalismo político. Contudo, a liberdade foi sacrificada no comunismo soviético.

Para os bolcheviques, o fim do liberalismo político parecia ser, inicialmente, apenas um método, mas se tornou um fim. Assim, Keynes de forma ousada, em palestra em Moscou, em 1925, afirmou: "Os extremos [...] são o fascismo de um lado e o leninismo do outro. De minha parte, não aceito nenhum dos dois” (Keynes, 2013j, p.438). E destacou a sua utopia: “[...] um regime que visará deliberadamente controlar e direcionar as forças econômicas para os interesses da justiça social e da estabilidade social” (Keynes, 2013j, p.439).

editorial. Em 1931, houve uma nova fusão: do fabiano New Stasteman com o The Nation and Athenaeum que foram rebatizados de New Statesman and Nation e Keynes passou a ser o seu chairman e Kingsley Martin, o seu editor. Foi nesse veículo que foi publicada a entrevista (anteriormente citada) de Stálin feita por Wells que recebeu comentários de Shaw e Keynes.

${ }^{29}$ Se chamavam fabianos em referência a Fábio, general romano, nascido três séculos antes de Cristo, conhecido por suas táticas de protelar ou retardar. Quando enfrentou adversários com números superiores de homens, Fábio buscou atacar os pontos vulneráveis do inimigo e aceitava confrontos unicamente em terrenos favoráveis às suas tropas. Só arriscaria uma batalha final quando o adversário estivesse desgastado. No site da Sociedade Fabiana (https://fabians.org.uk/about-us/our-history/) é apresentada sua história e origem do seu nome.

${ }^{30}$ Keynes apoiou de forma aberta o esquema proposto por Willian Beveridge em 1942, na Grã-Bretanha, que apresentava propostas de ampliação de oportunidades dentro do esquema já existente de seguridade social (ver Keynes, 2013k, p.204). Além disso, Keynes auxiliou na elaboração da viabilidade orçamentária do esquema de Beverigde (ver Keynes, 2013k, p.203-263). 


\section{CONSIDERAÇÕES FINAIS}

Para Keynes, luzes da cultura da esquerda comunista brilhavam no entendimento da operação de uma economia empresarial sugerido por Karl Marx: capitalistas produzem visando o lucro monetário e tal economia pode sofrer insuficiência de demanda. As sombras apareceriam nas consequências sugeridas: insatisfação crescente da classe trabalhadora e enfrentamentos violentos na busca pelo poder. As luzes estariam no diagnóstico e as sombras, nas possíveis consequências e métodos.

Keynes, tal como Marx, também construiu sua utopia. O artigo mais importante de Keynes que resumiu o seu sonho foi o Economic possibilities for our grandchildren (de 1930) (Keynes, 2013b, p.321-332). É uma sociedade onde seria desnecessário buscar o enriquecimento porque todas as restrições materiais estariam superadas: uma vida com bem-estar estaria garantida para todos. A avareza seria um vício, a usura uma contravenção e o amor pelo dinheiro seria detestável - e onde os mais sábios não se preocupariam com o futuro: era viver o hoje, sem inquietações (Keynes, 2013b, p.321).

O caminho proposto até a utopia distanciou Keynes de Marx, Lênin e Stálin. Lançou sombras na sua relação com a cultura da esquerda comunista, especialmente com os métodos utilizados na experiência soviética. Keynes considerava a liberdade um fim e não apenas um meio para que sua utopia fosse alcançada - a própria liberdade plena fazia parte da sua utopia.

Não era somente o horror com os métodos violentos que distanciou Keynes da cultura da esquerda comunista, mas também a identificação dos agentes transformadores. Keynes confiava numa vanguarda iluminada (culta) e não depositava esperanças, por considerá-lo despreparado, no proletariado. Pensava, por exemplo, que os rumos da economia deveriam ser atribuídos exclusivamente a especialistas (Keynes, 2013b, p.332).

A militância de Keynes para formar uma intelligentsia reformista e radical eram luzes coincidentes na sua relação com os fabianos. Na Grã-Bretanha, os fabianos tinham práticas e adotavam iniciativas coincidentes com Keynes. Por exemplo, fundaram a London School of Economics e convidaram Keynes para ali trabalhar; criaram um veículo público para o debate intelectual, o New Statastmen, que Keynes incorporou e veio a dirigi-lo (a partir de 1931).

Keynes não se opôs ao experimento soviético, não o avaliou com nenhum preconceito intelectual. Apenas analisou, com os olhos de um prático, seus métodos e resultados. Via que nesse experimento poderia emergir o ponto que considerava o auge de sua utopia: o fim do amor pelo dinheiro. Seria o auge porque o fim do amor pelo dinheiro somente poderia ocorrer quando houvesse segurança da vida material (no presente e no futuro). Por isso, Keynes disse que aceitaria trabalhar para os bolcheviques. Keynes viu no bolchevismo econômico alguma semente de esperança.

Keynes hoje é visto com muitas reservas por parte da esquerda, mas é visto com muita simpatia por outra parte. A esquerda rupturista, que prega a violência revolucionária, que justifica a falta de liberdade como método e que justifica os 
crimes do regime soviético, considera Keynes um adversário. As ideias de Keynes têm sido úteis a uma outra esquerda: uma esquerda libertária, reformista e radical.

Keynes não fez qualquer autorrotulação política/ideológica explícita e específica, além de se considerar um liberal radical. Vale, portanto, deixar para reflexão uma passagem do seu artigo Liberalism and Labour (de 1926), que talvez tenha sido o único momento onde Keynes foi mais explícito:

Tenho certeza que sou menos conservador em minhas inclinações do que a média dos eleitores trabalhistas [britânicos]; [...] A república da minha imaginação está na extrema esquerda do espaço celestial. (Keynes, 2013b, p.309)

\section{REFERÊNCIAS BIBLIOGRÁFICAS}

Albuquerque, E.M. (2005). Lições da tragédia: limites e contradições do progresso tecnológico na União Soviética. IN: Paula, J.A. (organizador), Adeus ao Desenvolvimento. Belo Horizonte: Autêntica.

Backhouse, R. E \&. Bateman, B.W. (2011). Capitalist revolutionary: John Maynard Keynes. Harvard University: Cambridge, Massachusetts.

Bresser-Pereira, L. C. (2006). O paradoxo da esquerda no Brasil. Novos Estudos CEBRAP, n 74. Disponível em: http://www.scielo.br/scielo.php?script=sci_arttext\&pid=S0101-33002006 000100003\&lng=en\&nrm=iso (Acesso em 20/08/2019)

Cardim de Carvalho, F. (2015). Liquidity Preference and Monetary Economics. Routeledge: New York. Cerqueira, H. (2015). Breve história da edição crítica das obras de Karl Marx. Revista de Economia Politica, 35(4), pp. 825-844.

Harrod, R.F. (1958). La Vida de John Maynard Keynes. México: Fondo de Cultura Económica.

Keynes, J. M. (2013a). The Collected Writings of John Maynard Keynes, Editado por D. E. Moggridge.

Vol. XXIX, The General Theory and After - a supplemet. London: Macmillan.

Keynes, J. M. (2013b). The Collected Writings of John Maynard Keynes, Editado por D.E.Moggridge. Vol. IX, Essays in Persuasion. London: Macmillan.

Keynes, J. M. (2013c). The Collected Writings of John Maynard Keynes, Editado por D. E. Moggridge. Vol. XXVIII, Social, Political and Literary Writings. London: Macmillan.

Keynes, J. M. (2013d). The Collected Writings of John Maynard Keynes, Editado por D. E. Moggridge.

Vol. X, Essays in Biography. London: Macmillan.

Keynes, J. M. (2013e). The Collected Writings of John Maynard Keynes, Editado por E. Johnson. Vol. XVI, Activities 1914 -1919: the Treasury and Versailles. London: Macmillan.

Keynes, J. M. (2013f). The Collected Writings of John Maynard Keynes, Editado por D. E. Moggridge. Vol. XXI, Activities 1931-1939: World Crises and Policies in Britain and America. London: Macmillan.

Keynes, J. M. (2013g). The Collected Writings of John Maynard Keynes, Editado por E. Johnson. Vol. XVII, Activities 1920-1922: Treaty Revision and Reconstruction. London: Macmillan.

Keynes, J. M. (2013h). The Collected Writings of John Maynard Keynes, Vol. II, The Economic Consequences of the Peace. London: Macmillan.

Keynes, J. M. (2013i). The Collected Writings of John Maynard Keynes, Editado por D. E. Moggridge. Vol. XIII, The General Theory and After - Part I Preparation. London: Macmillan. 
Keynes, J. M. (2013j). The Collected Writings of John Maynard Keynes, Editado por D. E. Moggridge. Vol. XIX, Activities 1922-1929 - The Return to Gold and Industrial Policy. London: Macmillan. Keynes, J. M. (2013k). The Collected Writings of John Maynard Keynes, editado por D. E. Moggridge, Vol. XXVII, Activities 1940-1946: Shaping the Post-War World: employment and commodities. London: Macmillan.

Keynes, J.M. (1973). The General Theory of Employment, Interest and Money. London: Macmillan. Lênin, V. (1917). As Tarefas do Proletariado na Presente Revolução. Disponível em: https://pcb.org.br/ portal/docs/astesesdeabril.pdf (acesso em 011/012019)

Moggridge, D.E. (1993). Keynes. London: Macmillan.

Marx, K. (1984). O Capital. - Livro I, Vol. I: o processo de produção do capital. São Paulo: Difel.

Marx, K. \& Engels, F. (1982). Manifesto do Partido Comunista. In: Obras Escolhidas - tomo I. Lisboa: Edições Avante.

Skidelsky, R. (1999). Keynes. Rio de Janeiro: Jorge Zahar Editor.

Skidelsky, R. (1994). John Maynard Keynes - The Economist as Savior 1920-1937. London: PaperMac.

Skidelsky, R. (1986). John Maynard Keynes - Esperanzas Frustradas 1883 -1920. Madrid: Alianza Editorial. 


\section{ERRATA \\ Brazilian Journal of Political Economy \\ Revista de Economia Política (2020) \\ http://dx.doi.org/10.1590/0101-31572020-3028}

No artigo Luzes e Sombras: um olhar de Keynes sobre a esquerda /Lights and Shadows: a Keynes's view on the left / João Sicsú, com número de DOI: <http://dx.doi.org/10.1590/0101-31572020-3025 >, publicado no periódico Brazilian Journal of Political Economy, v. 40 n. 3, pp. 433-584, nas páginas 550 e 553.

Na página 550, na nota de rodapé:

Onde se lia:

${ }^{30}$ Keynes apoiou de forma aberta o esquema proposto por Willian Beveridge em 1942, na Grã-Bretanha, que apresentava propostas de ampliação de oportunidades dentro do esquema já existente de seguridade social (ver Keynes, 2013g, p.204). Além disso, Keynes auxiliou na elaboração da viabilidade orçamentária do esquema de Beverigde (ver Keynes, 2013g, p.203-263).

\section{Leia-se:}

${ }^{30}$ Keynes apoiou de forma aberta o esquema proposto por Willian Beveridge em 1942, na Grã-Bretanha, que apresentava propostas de ampliação de oportunidades dentro do esquema já existente de seguridade social (ver Keynes, 2013k, p.204). Além disso, Keynes auxiliou na elaboração da viabilidade orçamentária do esquema de Beverigde (ver Keynes, 2013k, p.203-263).

Na página 553

Onde se lia:

Keynes, J. M. (2013k). The Collected Writings of John Maynard Keynes, Editado por D. E. Moggridge. Vol. XXIV, Activities 1944 -1946 - The Transition to Peace. London: Macmillan.

Leia-se:

Keynes, J. M. (2013k). The Collected Writings of John Maynard Keynes, editado por D. E. Moggridge, Vol. XXVII, Activities 1940-1946: Shaping the Post-War World: employment and commodities.London: Macmillan. 